\title{
Um conto soviético
}

Denise Regina de Sales

A tradução, segundo o modelo proposto por Jiři Levý, consiste em um processo de decisões consecutivas, cada uma delas determinante do passo subsequente. A partir dessa noção, comentamos aqui a tradução do russo para o português de um conto de Mikhail Zóschenko.

\section{Sobre o autor}

Mikhail Mikháilovitch Zóschenko (1895-1958) adotou a literatura como profissão no decênio de 1920. Em 1922, depois de publicar contos em revistas e jornais, lançou o primeiro livro, Рассказы Назара Ильича господина Синебрюхова [Contos de Názar Ilitch, o senhor Sinebriukhov], tornando-se imediatamente muito popular. Para atingir a grande massa de leitores, optou pela linguagem coloquial. Em vários contos, o narrador em primeira pessoa colore o relato com expressões populares, mescladas a termos e chavões do jargão político e econômico da época, e isso produz construções inusitadas, mas perfeitamente compreensíveis, além de saborosas.

As personagens são, em sua maioria, pessoas simples: o morador do apartamento comunitário, o operário, o mujique, o cobrador do bonde, o desempregado. $\mathrm{Na}$ ficção, eles vivem as mazelas do cotidiano. Não realizam proezas, não pretendem mudar o mundo, não discutem grandes questões existenciais; simplesmente levam a vida, cuidam de acender a vela para os santos, juntar dinheiro para comprar um cavalo, reclamar dos vizinhos, vangloriar-se das próprias doenças. As histórias, episódios da vida cotidiana, acontecem no metrô, no apartamento coletivo, na sala de espera do consultório, no tribunal, na estação ferroviária, no parque, na igreja, no teatro. 
Como o próprio escritor afirmava, a sua produção literária exigiu um trabalho cuidadoso da linguagem: "Era preciso mudar profundamente toda a sintaxe para tornar a coisa literária simples e acessível ao novo leitor. A prova de que não me enganei foram as enormes tiragens de meus livros. Portanto, a linguagem que adotei e que, num primeiro momento, pareceu risível e estropiada à crítica, na realidade, é extremamente simples e natural."

A simplicidade e a naturalidade predominam em toda a obra de Zóschenko, em suas novelas, peças e contos. Nesses últimos, acompanhadas da brevidade, conferem a seus contos curtos um aspecto singular, facilmente reconhecido pelos leitores da época. Para análise neste artigo, tomamos um desses contos.

\section{Sobre o conto}

O conto Баба [baba], traduzido por "Mulherzinha", foi escrito em 1923. A história se passa no tribunal, onde o juiz interroga um casal acusado de fabricação clandestina de samogón, bebida alcoólica preparada artesanalmente a partir da fermentação de pão, batata etc. Do pouco que é dito, deduzimos que havia uma combinação prévia do casal para que a esposa assumisse toda a culpa, mas o plano vai por água abaixo assim que o marido começa a ofendê-la, fazendo comentários sobre a sua idade e aparência. O juiz joga a isca e fica à espera dos resultados. "O que houve, incompatibilidade de gênios?”, pergunta ele. E, a partir daí, as desavenças entre marido e mulher provocam o fim do pacto e o desmascaramento do marido, que sabia de tudo e até comprara o aparelho para fabricar a aguardente.

No conto, a sátira individual-psicológica, montada no enredo da quebra do pacto entre marido e mulher, funde-se à sátira social. Vale lembrar que na União Soviética do início da década de 1920 houve proibição da fabricação caseira de aguardente. Nos primeiros anos pós-Revolução, essa infração, de acordo com um decreto do Comitê Central Executivo da República da Rússia, podia resultar no confisco dos bens e em até dez anos de prisão. É dessa época, por exemplo, o comunicado do Comitê Militar Revolucionário da região de Donbass que incluiu a bebedeira no rol das atividades contrarrevolucionárias.

1 Citado por Iuri Tomachévski no prefácio a Sobranie Sotchiniéni [Obras reunidas]. Leningrado: Khudojestvennaia Literatura, 1986. p. 9. 


\section{O conto}

\section{Баба}

Судья пристально смотрит на обвиняемых. Их двое - муж и жена. Самогонщики.

- Так как же, - спрашивает судья, - значит, вы, обвиняемый, не признаете себя виноватым?

- Нету, - говорит подсудимый, - не признаю. .. Она во всем виновата. Она пущай и расплачивается. Я ничего не знаю про это. . .

- Позвольте, - удивляется судья, - как же так? Вы живете с женой в одной квартире и ничего не знаете. Не знаете даже, чем занимается ваша жена.

- Не знаю, гражданин судья... Она во всем...

- Странно, - говорит судья. - Подсудимая, что вы скажете?

- Верно уж, начальник судья, верно... Я во всем виновата... Меня и казните... Он не касается.

- Гражданка, - говорит судья, - если вы хотите выгородить своего мужа, то напрасно. Суд все равно разберет. . . Вы только задерживаете дело. .. Вы сами посудите: не могу же я поверить, что муж живет в одной квартире и ничего не знает... Что, вы не живете с ним, что ли?

Подсудимая молчит. Муж радостно кивает головой.

- Не живу я с ней, - говорит он, - вот именно: не живу. Некоторые думают, что я живу, а я нет... Она во все виновата...

- Верно это? - спрашивает судья у подсудимой.

- Уж верно... Меня одну казните, он не причастен.

- Вот как! - говорит судья. - Не живете... Что ж, вы характером не сошлись?

Подсудимый кивает головой.

- Характером, гражданин судья, и вообще... Она и старше меня и...

- То есть, как это старше? - спрашивает подсудимая. - Ровесники мы с ним, гражданин судья..... На месяц-то всего я и старше.

- Это верно, - говорит подсудимый, - на месяц только... Это она правильно, гражданин судья... Ну, а для бабы каждый месяц, что год... В сорок-то лет. 
- И нету сорока. Врет он, гражданин судья.

- Ну хоть и нету, а для бабы и тридцать девять - возраст. И волос все-таки седой к сорока-то и вообще...

- Что вообще? - возмущается подсудимая. - Ты договаривай! Нечего меня перед народом страмить. Что вообще?

Судья улыбается.

- Ничего, Марусечка... Я только так. Я говорю - вообще... и кожа уж не та, и морщинки, ежели, скажем, в сорок-то лет. .. Не живу я с ней, гражданин судья...

- Ах, вот как! - кричит подсудимая. - Кожа тебе не по скусу? Морщинки тебе, морда собачья, не ндравятся? Перед народом меня страмить выдумал... Врет он, граждане судьи! Живет он со мной, сукин сын. Живет. И самогонный аппарат сам покупал... Я ж для него, сукиного сына, кровь порчу, спасаю его, а он вот что! Страмить... Пущай вместе казнят...

Подсудимая плачет, громко сморкаясь в платок. Подсудимый оторопело смотрит на жену. Потом с отчаянием машет рукой.

- Баба, баба и есть, чортова баба. .. Пущай уж, гражданин судья. . . я тоже... И я виноват. Пущай уж... У-у, стерва...

Судья совещается с заседателями.

\section{A tradução}

\section{Mulherzinha}

O juiz olha atentamente os acusados. São dois: marido e mulher. Respondem por produção clandestina de samogón, aguardente caseira.

- Então é isso? - pergunta o juiz. - Quer dizer: o senhor acusado não reconhece a culpa?

- Não - diz o réu -, não reconheço. Ela é culpada de tudo. Então ela paga. Eu não sabia de nada.

- Se me permite - surpreende-se o juiz -, como isso é possível? O senhor mora com a esposa na mesma casa e não sabe de nada? Não sabe nem mesmo o que ela faz?

- Não sei, não, cidadão juiz... Ela é culpada...

- Estranho - diz o juiz. - A ré, o que diz? 
- É verdade mesmo, chefe juiz, tudo verdade... Eu sou culpada de tudo... Pode executar... Ele não tem nada...

- Cidadã - diz o juiz -, não adianta tentar proteger seu marido, será inútil. A justiça vai descobrir tudo de qualquer modo... A senhora apenas atrasa o caso... Pense bem: eu não posso acreditar que seu marido mora com a senhora em uma mesma casa e não saiba de nada... E, então, a senhora mora ou não mora com ele?

A ré fica calada. O marido balança a cabeça, animado.

- Não, não moro com ela - diz ele. - É isso mesmo: não moro, não. Uns acham que eu moro, mas eu não moro... Ela é culpada de tudo.

- É verdade isso? - pergunta o juiz à ré.

- É verdade mesmo... Pode executar só eu, ele não comungou nisso.

- Então é isso? - diz o juiz. - Não mora... O que aconteceu, incompatibilidade de gênios?

O réu balança a cabeça.

- De gênio, cidadão juiz, e além do mais... Ela é mais velha que eu, e...

- Como assim, mais velha? - pergunta a ré. - A idade nossa é igual, cidadão juiz... Só um mês eu sou mais velha.

- Isso, lá, é verdade - diz o réu. - Só um mês... Nisso ela está certa, cidadão juiz... Mas pra mulher, um mês é como um ano, né? Com quarenta, então...

- Eu não tenho quarenta. Ele está mentindo, cidadão juiz.

- Pode até não ter, mas, pra mulher, trinta e nove, he, he... já é muito. E perto dos quarenta, o cabelo... e ainda...

- E ainda o quê? - revolta-se a ré - Anda, fala! Não tem que acaçoar de mim na frente do público. E ainda o quê?

O juiz sorri.

- Nada, Marúsetchka... Falei por falar. E ainda... a pele já não é mais aquela, tem rugas, pois então... chegando os quarenta... Não, eu não moro com ela, cidadão juiz...

- Ah, é assim? - grita a ré. - A pele não está pro seu gosto? Então, fuça de porco, não gosta das rugas? Veio querendo acaçoar de mim na frente do público... Ele está mentindo, cidadão juiz! Mora comigo esse filho duma cadela. Mora, sim. E o aparelho de samogón ele é que comprou... Eu dou o sangue por esse filho duma cadela, pra salvar ele, e vejam só o que ele faz: acaçoa de mim. Pode executar nós dois.

A ré chora, assoa com força no lenço. O réu fita a mulher, perplexo. Depois, já indiferente, dá de ombros. 
- Mulherzinha... É uma mulherzinha mesmo, mulherzinha dos diabos... Então deixa, cidadão juiz... eu também... eu também sou culpado... Deixa assim... Ah, peste...

O juiz consulta os jurados.

\section{Sobre a tradução}

A tradução apresentada aqui foi feita inicialmente para a dissertação de mestrado $A$ sátira e o bumor nos contos de Mikbail Zócbtchenko ${ }^{2}$; depois, foi reelaborada na disciplina "Teoria e prática da tradução", ministrada por Aurora Fornoni Bernardini. Dadas as decisões da tradutora, somadas às sugestões e colaborações de professores e colegas, o texto em português pode ser analisado de acordo com o modelo sugerido por Jiři Levý, que considera a tradução como um processo decisório, de movimentos semelhantes aos do xadrez - as alternativas escolhidas pelo tradutor predeterminariam, sucessivamente, o rumo do texto de chegada. Nas palavras do próprio Levý:

Do ponto de vista do trabalho do tradutor, a qualquer momento desse trabalho (isto é, do ponto de vista pragmático), traduzir é UM PROCESSO DE TOMADA DE DECISÃO: uma série de um certo número de situações consecutivas - movimentos, como em um jogo - que impõem ao tradutor a necessidade de escolher dentre um certo número (muitas vezes exatamente definível) de alternativas. (LEVÝ, p. 72)

Para o teórico, os componentes do problema decisório são a situação, os paradigmas e as instruções. A situação é a própria condição da tradução; os paradigmas, as soluções tradutórias possíveis; e as instruções, os princípios norteadores da formação do paradigma e da escolha do tradutor.

Vejamos como essas questões se colocam desde o título. A palavra “баба", no dicionário russo, tem a seguinte definição ${ }^{3}$ : "1. Camponesa casada e também qualquer mulher do povo (expressão popular). 2. Referente à mulher em geral (às vezes, em tom de menosprezo ou pilhéria) (expressão popular). 3. O mesmo que esposa (na acepção 1) (expressão popular e regionalismo). 4. O mesmo que avó (na acepção 2) (expressão popular e regionalismo); no discurso infantil, o mesmo que vovó (na acepção 1). Ex.: Era uma vez um casal - vovô e vovó. 5. (Sen-

2 A diferença de grafia deve-se à mudança na transliteração da letra $\amalg$ [de “chtch" para “sch”], de acordo com a tabela do Curso de Russo da USP.

3 Em Tolkovyi slovar russkovo iazykea [Dicionário geral da língua russa]. Moscou: Azbukovnik, 1997. 
tido figurado) Homem medroso e fraco de caráter (coloquial). Nesse caso, em razão do enredo do conto, que discutiremos mais adiante, é interessante destacar, ainda, a expressão: “бабыи сказки” [babi skazki] = "balela" (afirmação ou boato infundado ou falso).

Além do sentido dicionarizado do termo, precisamos buscar o seu significado específico na obra. Para isso levamos em conta não apenas o título, mas o conto como um todo. A palavra "баба" [baba] aparece na última fala do marido, em referência à mulher (“Баба, баба и есть, чертова баба...” [baba, baba e est, tchertova baba], traduzido do seguinte modo: "Mulherzinha, é uma mulherzinha mesmo, mulherzinha dos diabos"). Portanto, podemos deduzir que o título antecipa a fala da personagem, porém com certo suspense, pois ainda não se tem certeza do sentido que o termo vai adquirir.

No modelo de Jiřŕ Levý, essas e outras considerações possíveis são as instruções, enquanto as possibilidades de tradução consistem nos paradigmas. Nesse caso, o sistema de instruções é muito rico (inclui a análise não só do termo original, mas também da tradução escolhida e das opções tradutórias aceitáveis), enquanto o sistema de paradigmas mostra-se bem restrito. Traduzir por "mulher" neutralizaria uma série de significados adicionais. Entretanto, nas discussões em sala de aula, foram levantados argumentos contra o uso de "mulherzinha":

- Баба [baba] é também o título de um conto do escritor russo Antón Tchékhov (1860 - 1904), traduzido no Brasil como "Mulherio".

- "Mulherzinha" não abrange o principal significado do termo russo (acepção 1).

Em defesa de "mulherzinha", contra-argumenta-se:

- Embora seja possível usar "mulherio" no conto de Zóschenko, o seu sentido plural extrapolaria o original, não apenas em relação ao próprio termo, que em russo está no singular, mas sobretudo quanto ao sentido, pois o enredo expressa justamente uma questão específica, e o personagem, um homem do povo, ao xingar a esposa, não faz referência à classe das mulheres, mas, sim, a sua companheira.

- Realmente, "mulherzinha" inclui as seguintes acepções": 1. Uso informal. mulher pequena; 2. menina precocemente desenvolvida, com gestual e formas que the

4 No Dicionário eletrônico Houaiss da lingua portuguesa 1.0. 
dão aparência adulta. 3. tratamento afetuoso atribuído à esposa no convívio familiar. 4. Uso: pejorativo. mulher sem prestígio social, de classe inferior. 4.1. Uso: pejorativo. mulher ordinária, vulgar, desprezível. 5. Uso:pejorativo. mulher bisbilhoteira, metediça, enxerida. 6. Uso: pejorativo qualificativo depreciativo, atribuído ao homem afeminado. Porém, em português, as acepções 4, 4.1 e 5 dão conta do principal significado encontrado no conto.

Outra possibilidade levantada nas discussões com colegas e professores foi a simples transliteração de “баба", versão feminina de мужик [mujik], registrado como "mujique" em dicionários brasileiros". No caso do conto de Zóchtchenko, julgamos ser mais adequado traduzir "баба" por "mulherzinha" por três razões:

- "Mujique" não se aproxima sonoramente de nenhum vocábulo frequente na língua portuguesa falada no Brasil, enquanto "baba" gera automaticamente outras associações não sugeridas no texto original.

- Como acabamos de mencionar, a acepção mais importante no conto não é a 1 (camponesa casada e também qualquer mulher do povo), mas a 3 (referente à mulher em geral, às vezes, em tom de menosprezo ou pilhéria).

- Manter "baba" implicaria numa nota de rodapé, uma vez que esse termo ainda não está dicionarizado, o que iria contra uma das orientações gerais (listadas mais adiante), ou seja, não usar notas para não quebrar o ritmo coloquial e dinâmico do texto.

No modelo de Levý, as instruções são definitórias ou seletivas. As primeiras, como o nome indica, referem-se à definição do paradigma; elas qualificam e definem o paradigma. As últimas fundamentam a escolha do tradutor a partir das alternativas possíveis. O tradutor, na posição de intérprete da obra a ser traduzida, "tem de escolher dentre um conjunto de possíveis significados da palavra ou motivo, dentre as diferentes concepções de um personagem, do estilo ou das opiniões filosóficas do autor" (LEVÝ, p. 74)

$\mathrm{Na}$ tradução do conto "Mulherzinha", levando-se em conta as características do autor e do conto, apontadas, respectivamente em "Sobre o autor" e "Sobre o conto", as decisões preliminares foram:

5 No dicionário citado na nota 5: "1. camponês russo de antes da revolução de 1917. 2. Derivação: por extensão de sentido. homem rude, do povo”. 
- Não usar notas de rodapé.

- Entre opções equivalentes, escolher sempre a mais curta.

- Entre ser "fiel" ao original e expressar a ideia de modo fluente na língua de chegada, ficar com a segunda opção.

Um aspecto essencial consistiu na preservação das características que marcam mais profundamente a prosa de Zóschenko: a brevidade, a coloquialidade e a leveza das construções. O próprio autor, em várias oportunidades, destacou o empenho em simplificar as estruturas sintáticas e em imprimir um ritmo coloquial não só às falas das personagens, mas também às intervenções do narrador. Além disso, a exclusão de notas preserva o caráter cômico, pois o riso flui no correr ininterrupto da leitura.

Outros aspectos do conto também foram avaliados para orientar a tradução. Aspectos da elaboração do texto são especialmente importantes. Em primeiro lugar, a narrativa baseia-se na linguagem. Por meio da linguagem podemos deduzir que:

1. as personagens acusadas, marido e mulher, são pessoas simples, provavelmente de origem camponesa.

2. a tática do juiz para extrair a verdade envolve, logo no início, a mudança do próprio discurso, aproximando-o do discurso dos acusados.

3. a ré está intimidada pelo aparato do tribunal e pela gravidade do delito e expressa isso (nem sempre com bons resultados) na forma como se dirige ao juiz e na hesitação. A expressão начальник судья [natchalnik sudia], por exemplo, reflete essa característica. A estranheza da combinação existe também em russo e, na tradução, foram usadas as primeiras acepções dicionarizadas das duas palavras: "chefe" e "juiz".

4. o narrador contamina-se pela linguagem dos acusados, por ser porta-voz deles.

Para recuperar os recursos estilísticos de produção do humor devemos respeitar:

1. a utilização de palavras e expressões de universos linguísticos diferentes, às vezes deslocadas do seu contexto usual por ignorância ou ingenuidade do falante. No discurso do juiz, é importante manter a linguagem jurídica e o jargão profissional. $\mathrm{Na}$ fala dos acusados, os termos deslocados ("comungar", "executar", etc.) 
2. a quebra da expectativa

3. o processo gradual de desmascaramento do marido.

Além desses fatores, privilegiou-se a manutenção de elementos russosoviéticos que situam o relato histórica e culturalmente. Vejamos dois deles e o modo como foram expressos em português.

O primeiro encontra-se na terceira sentença do original, composta de uma única palavra Самогонщики [samogonschiki]. No processo decisório, optamos por sacrificar o aspecto da brevidade, mantido em outras passagens (como nas duas frases anteriores) e acordado como regra geral, em nome da preservação do termo samogon, típico da cultura russa. Sozinho, ele não diria nada ao leitor brasileiro, daí o acréscimo explicativo "aguardente caseira". Faltam-nos, entretanto, mais dois elementos - um morfossemântico, outro cultural. O primeiro é o sufixo russo "schik", que corresponde ao nosso "eiro", indicando profissões, ocupações ou ofícios. Portanto, um dos paradigmas de samogonschiki (o último " $i$ ” indica o plural) seria "fabricantes [fazedores, produtores] de samogon".

O segundo elemento, muito mais facilmente reconhecido por um russo do que por um brasileiro, é o fato de que, a partir de dezembro de 1917, houve intensa repressão ao comércio de aguardente na Rússia e a bebedeira chegou a ganhar status de atividade contrarrevolucionária, ou seja, a venda de samogon podia, sim, levar os envolvidos ao tribunal e resultar em sentenças pesadas, que, na mente das pessoas simples, expressava-se como "execução". Desse modo, a terceira frase do texto original, composta de uma única palavra, foi traduzida por "Respondem por produção clandestina de samogón, aguardente caseira".

O segundo exemplo de elemento russo-soviético é a forma de tratamento "cidadão" e "cidadã". Ainda que não seja imediatamente reconhecida como soviética pelo leitor brasileiro, mais acostumado ao termo "camarada", tradução de товарищ [tovarisch], a fórmula гражданин [grajdanin] е гражданка [grajdanka], respectivamente, cidadão e cidadã, tornou-se popular numa época em que "senhor" e "senhora", como marca da divisão de classes, tinham sido abolidos.

Em resumo, nesses exemplos e explicitações, com destaque para o encadeamento do processo de decisões de tradução, fica clara a complexidade da prática tradutória, que envolve a operação de interpretação, o elencar de alternativas na língua de chegada e, finalmente, a escolha da melhor alternativa segundo os critérios do tradutor. 


\section{Referências}

LEVÝ, Jiř́. "Translation as a decision process. A tradução como um processo de tomada de decisão”. Trad. Gustavo Althoff e Cristiane Vidal. In: Sciencia Traductionis, n. 11, 2012. Disponível em http://dx.doi.org/10.5007/1980-4237.2012n11p72 Consulta feita em 01.02.2013.

PROPP, Vladímir. Comicidade e riso, trad. Aurora Fornoni Bernardini e Homero Freitas de Andrade. São Paulo: Editora Ática, 1992.

ZÓSCHENKO, Mikhail Mikháilovitch. Sobranie Sotchiniéni [Obras reunidas]. Leningrado: Khudojestvennaia literatura, 1986. 